\title{
In vitro Antifungal Activity of Cistus creticus L. Against Plant Pathogenic Fungi
}

\author{
Ayşegül Çaşkurlu', Ayşe Esra Karadağ ${ }^{1 *}, 2$, Yavuz Bülent Köse ${ }^{3}$, Fatma Tosun ${ }^{1}$ \\ 1lstanbul Medipol University, School of Pharmacy, Department of PharmacognosyPharmacognosy, İstanbul, Turkey \\ 2 Anadolu University, Graduate School of Health Sciences, Department of Pharmacognosy, Eskişehir, Turkey \\ 3 Anadolu University, Faculty of Pharmacy, Department of Pharmaceutical Botany, Eskişehir, Turkey
}

\begin{abstract}
Cistus creticus L. is a well-known member of the Cistaceae family. In this present study, methanol extract of aerial parts of $C$. creticus was evaluated for its antifungal activity against plant pathogenic fungi such as Fusarium moniliforme NRRL 2374, Fusarium culmorum NRRL 3288, Alternaria alternata ATCC 6663, and Botrytis cinerea AHU 9424, respectively. The in vitro antifungal activity of $C$. creticus extract was determined by calculating mycelial growth inhibition. It was demonstrated that methanol extract of $C$. creticus has shown antifungal activity on $F$. moniliforme (36,7\%) and B. cinerea (30,2\%). Moreover, we are planning to evaluate the active fractions which are responsible for the antifungal activity in further studies.
\end{abstract}

Keywords: Cistaceae, Cistus creticus L., antifungal, plant pathogenic fungi

\section{INTRODUCTION}

Cistaceae family members occur mostly in temperate and subtropical regions such as European-African and Mediterranean ecosystems ${ }^{1}$. Cistus species naturally grown in Turkey are represented by five species and known as "tüylü laden, pamuklu, pamukluk" ${ }^{2-4}$. The natural habitat for Cistus species is the Mediterranean area in Turkey. As a result of various ethnobotanical studies, it is stated that Cistus creticus L. is used for hemostatic and wound healing purposes in different localities in Turkey ${ }^{4-6}$. Also, in previous studies shown that $C$. creticus various extracts have in vitro antibacterial, antifungal, anti-Borrelia, cytotoxic, anti-inflammatory, antiviral, antithrombotic, antiatherogenic, antidiabetic, cytotoxic, antioxidant and antiulcer activities ${ }^{7-19}$. Also, the study which is done

*Corresponding author: Ayşe Esra Karadağ, e-mail: aeguler@medipol.edu.tr Ayşegül Çaşkurlu ORCID Number: 0000-0001-7277-920X Ayşe Esra Karadağ ORCID Number: 0000-0002-3412-0807

Yavuz Bülent Köse ORCID Number: 0000-0002-3060-7271 Fatma Tosun ORCID Number: 0000-0003-2533-5141

(Received 27 December 2019, accepted 08 January 2020) 
by Karim and co-workers shows that Cistus species may be effective against another important plant pathogenic fungus Geotrichum citri-aurantii ${ }^{20-21}$.

Plant diseases are very important factors in agricultural production and phytopathogenic fungi of different genera, infect countless crops. Particularly, some Fusarium species and Botrytis cinerea lead to very important plant diseases that cause economical losses in agriculture ${ }^{22}$. Fusarium and Botrytis species are especially pathogenic microorganisms against vegetables and fruits cultivated as food ${ }^{23-24}$. Therefore, especially the antifungal agents investigated in this study aim to provide a solution to an important economic problem encountered in the production of vegetables and fruits. In recent years, the efficiency of fungicides traditionally used to control plant diseases has dramatically diminished. At the same time, improper use of conventional fungicides such as dicarboximides and benzimidazoles have caused an increase in drug resistance against fungal strains ${ }^{25}$. To overcome this, the discovery of new natural antifungal agents which can replace the current therapeutic strategies is therefore very important.

The antifungal activity of $C$. creticus methanol extract on various fungi species is investigated in this present study. The aim is to discuss whether it can be used to solve agricultural problems by considering the demand for herbal medicine.

\section{METHODOLOGY}

\section{Collection of Plant Material and Extraction}

C. creticus aerial parts were collected in May 2018 at the time of flowering from Çavuşbaşı Village/ Beykoz in Istanbul. Plant was identified by Prof. Yavuz Bülent Köse and voucher specimen has been deposited at Herbarium of Anadolu University, Eskişehir, Turkey. (Voucher specimen no. ESSE: 15549). Air-dried plant samples were stored under appropriate conditions and powdered before use.

Extraction prepared from the plant material by maceration with methanol. The plant extract filtered from the filter paper after consumption was concentrated through rotavapor. The concentrated extract was kept closed in $+2 /+8^{\circ} \mathrm{C}$ conditions until it was used.

\section{Antifungal Activity}

Poison PDA technique was used for antifungal activity studies ${ }^{26}$. Antifungal evaluation of plant extracts was carried out on in vitro mycelial growth of plant pathogenic fungi Fusarium moniliforme NRRL 2374, Fusarium culmorum NRRL 3288, Alternaria alternata ATCC 6663, and Botrytis cinerea AHU 9424. 
$50 \mathrm{~mL}$ of PDA was dissolved in $100 \mathrm{~mL}$ water in a flask. The flask was sterilized for 20 minutes and kept under the sterilized hood to cool to $60^{\circ} \mathrm{C}$. Then, extracts were added to this flask and shaken gently to prepare PDA containing the extract. Ketaconazole was used for positive control and DMSO was used for negative control. A 4-millimeter PDA cake from culture medium was placed in the center of each Petri dish for each experiment. The Petri dishes were incubated in an oven at $25^{-27}{ }^{\circ} \mathrm{C}$ for 5 days. During the incubation, minimum and maximum diameters of the micelle growth of each pet were measured and recorded (Figure 1). The percentage of the inhibition of the mycelial growth (I) due to different treatments was calculated on the formula:

$\mathrm{I}(\%)=(1-\mathrm{dt} / \mathrm{dc}){ }^{*} 100(\%)$

Where, dc is the average fungal colony diameter measured in the control plate, with no treatment,

$d_{t}$ is the average fungal colony diameter measured in treated plates ${ }^{27}$.

\section{RESULTS AND DISCUSSION}

The antifungal activity of the extract was tested with mycelial growth rate method against $F$. moniliforme, $F$. culmorum, B. cinerea, and A. alternate (Figure 1). The provided data were studied in triplicates and the mean of the results was calculated by standard error. The results were compared to ketoconazole, which is current antifungal drugs, as shown Figure 2.

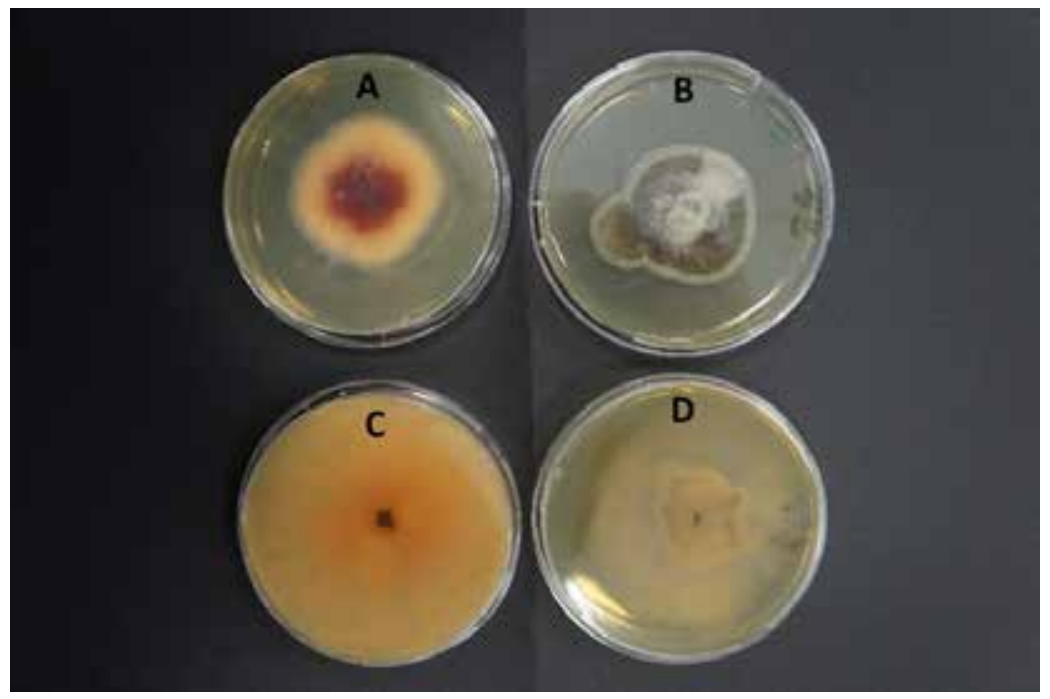

Figure 1. Mycelial growth results of fungi in extract-treated media (A: F. muniliforme, $\mathrm{B}: A$. alternata, C: F. culmorum, D: B. cinerea) 
B. cinerea is a fungus which is present in damp climates and subtropical regions. It survives on many plants as a facultative parasite and might cause diseases on the grapes, strawberries, squashes, and lettuces. Especially, it infects and harms wine grapes and causes a significant economic loss after harvesting the fruits ${ }^{28}$. Therefore, it is extremely important to develop an effective fungicide agent against these plant pathogens and especially compounds. $C$. creticus methanol extract shown $30,2 \%$ inhibition against $B$. cinerea. It can be considered with this result that the $C$. creticus methanol extract can be added to increase the effect on antifungal agents against $B$. cinerea.

F. moniliforme causes ear rot and stalk rot of corn and infection of corn kernels that is widespread in agricultural area ${ }^{29}$. Therefore, these fungi cause considerable big economic losses. Due to increased antifungal resistance in these fungi strains, it is very important to discover and develop new antifungal agents. According to the results of this study, $C$. creticus methanol extract shows $36,7 \%$ mycelial growth inhibition against $F$. moniliforme. The percent inhibition of the C. creticus extract against other microorganisms $F$. culmorum and A. alternata were found to be $5.55 \%$ and $8.75 \%$, respectively.

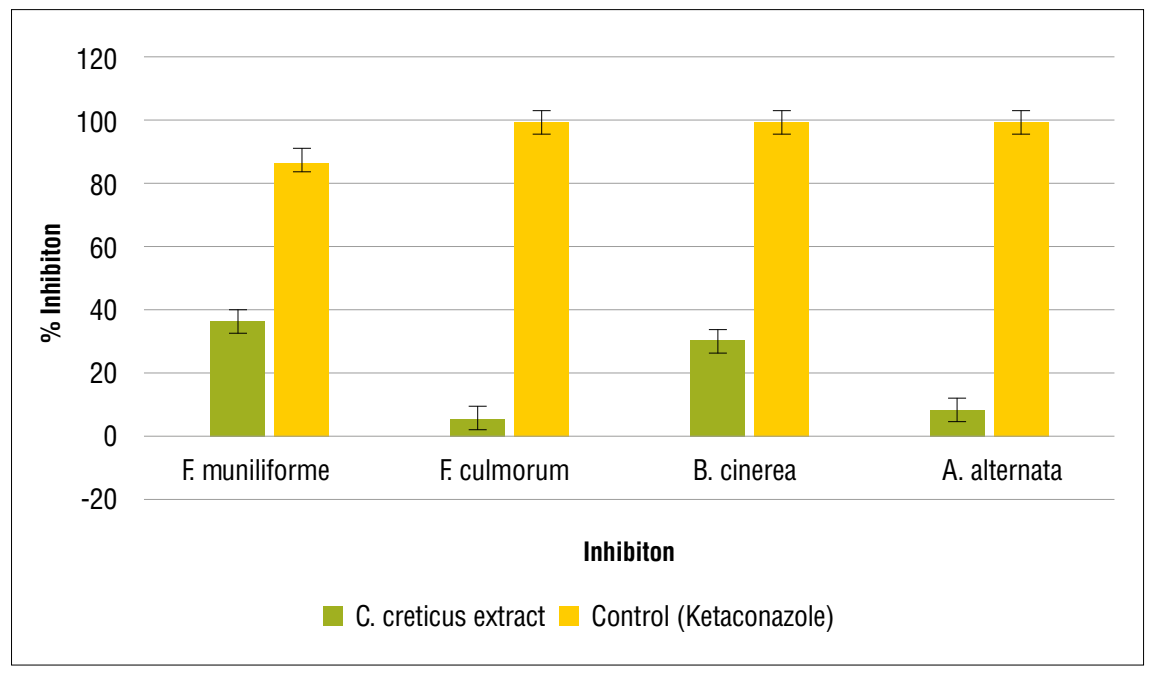

Figure 2. Mycelial growth \% inhibition of $\mathrm{C}$. creticus extract against tested plant pathogenic fungi

Previous studies against G. citri-aurantii, another plant pathogen fungus, suggest that some Cistus species can be used in the agricultural field ${ }^{20,21}$. In addition, it has been shown in this study that extracts, sub-extracts or fractions obtained from $C$. creticus species can be developed antifungally against $B$. cinerea and $F$. muniliforme fungi. 
In this study, the obtained results evidently may provide industrial advantages especially with combinations of the various antifungal agent with $C$. creticus methanol extract that can be used as pesticide. Therefore, these results can help the agricultural economy in the world for the development of potential and natural agrochemicals. More study needs to be conducted isolation and identification of responsible secondary metabolites from the extract. 


\section{REFERENCES}

1. Guzmán, B.; Vargas, P. Historical biogeography and character evolution of Cistaceae (Malvales) based on analysis of plastid rbcL and trnL-trnF sequences. Org. Divers. Evol. 2009, 9, 83-99.

2. Coode, M.J.E. Cistaceae. P. Davis (Ed.), Flora of Turkey and the East Aegean Islands, Edinburgh: Edinburgh University Press, 1965, 506-523.

3. Coode, M.J.E. Cistaceae. P. Davis, Mill, R., Tan, K. (Ed.). Flora of Turkey and the East Aegean Islands, Edinburgh: Edinburgh University Pres, 1988, 10, 61.

4. Gürdal, B.; Kültür, Ş. An ethnobotanical study of medicinal plants in Marmaris (Muğla, Turkey). J. Ethnopharmacol. 2013, 146, 113-126.

5. Honda, G.; Yeşilada, E.; Tabata, M.; Sezik, E.; Fujita, T.; Takeda, Y. Traditional medicine in Turkey VI. Folk medicine in West Anatolia: Afyon, Kütahya, Denizli, Muğla, Aydin provinces. J. Ethnopharmacol. 1996, 53, 75-87.

6. Tuzlacı, E.; Aymaz, P. E. Turkish folk medicinal plants, Part IV: Gönen (Balıkesir). Fitoterapia. 2001, 72, 323-343.

7. Attaguile, G.; Perticone, G.; Mania, G.; Savoca, F.; Pennisi, G.; Salomone, S. Cistus incanus and Cistus monspeliensis inhibit the contractile response in isolated rat smooth muscle. $J$. Ethnopharmacol. 2004, 92, 245-250.

8. Rauwald, H. W.; Liebold, T.; Grötzinger, K.; Lehmann, J.; Kuchta, K. Labdanum and Labdanes of Cistus creticus and C. ladanifer: Anti-Borrelia Activity and its Phytochemical Profiling. Phytomedicine. 2019, 152977.

9. Kılıç, D. D.; Sırıken, B.; Ertürk, Ö.; Tanrıkulu, G.; Gül, M.; Baskan, C. Antibacterial, Antioxidant and DNA Interaction Properties of Cistus creticus L. Extracts. J. Int. Environ. Appl. Sci., 2019, 14, 110-115.

10. Kuchta, K.; Tung, N. H.; Ota, T.; Raekiansyah, M.; Grötzinger, K.; Rausch, H.; Morita, K. The old pharmaceutical oleoresin labdanum of Cistus creticus L. exerts pronounced in vitro anti-dengue virus activity. J. Ethnopharmacol. 2019, 112316.

11. Mastino, P. M.; Mauro, M.; Jean, C.; Juliano, C.; Marianna, U. Analysis and Potential Antimicrobial Activity of Phenolic Compounds in the Extracts of Cistus Creticus Subspecies from Sardinia. Nat. Prod. J. 2018, 8, 166-174.

12. Vasiliki, G.; Charalampia, D.; Haralabos, K. C. In vitro antioxidant, antithrombotic, antiatherogenic and antidiabetic activities of Urtica dioica, Sideritis euboea and Cistus creticus water extracts and investigation of pasta fortification with the most bioactive one. Curr. Pharm. Biotechno. 2019, 20, 874-880.

13. Stępień, A. E.; Ewa, A. Cytotoxic and anti-cancer activity of the Cistus species of herbal plants. Eur. J. Clin. Exp. Med. 2017, 165-168.

14. Bayraktar, O; Altıok, E.; Yılmazer, Ö.; Ruscuklu, D.; Buyukoz, M. Y. Antioxidant, antimicrobial and cytotoxic activities of extracts from some selected mediterranean shrub species (Maquis). Biointerface Res. Appl. Chem. 2016, 6, 1437-1444.

15. Guvenc, A.; Yildiz, S.; Ozkan, A.M.; Erdurak, C.S.; Coskun, M.; Yilmaz, G. Antimicrobiological studies on Turkish Cistus species. Pharm. Biol. 2005, 43, 178-183.

16. Yesilada, E.; Gurbuz, I.; Ergun, E. Effects of Cistus laurifolius L flowers on gastric and duodenal lesions. J. Ethnopharmacol. 1997, 55, 201-211.

17. Yesilada, E.; Ustun, O.; Sezik, E.; Takaishi, Y.; Ono, Y.; Honda, G. Inhibitory effects of Turk- 
ish folk remedies on inflammatory cytokines: interleukin- 1alpha, interleukin-1beta and tumor necrosis factor alpha. J. Ethnopharmacol. 1997, 58, 59-73.

18. Yeşilada, E.; Gürbüz, I.; Shibata, H. Screening of Turkish anti-ulcerogenic folk remedies for anti-Helicobacter pylori activity. J. Ethnopharmacol. 1999, 66, 289-293.

19. Yeşilada, E.; Honda, G.; Sezik, E.; Tabata, M.; Fujita, T.; Tanaka, T. Traditional medicine in Turkey. V. Folk medicine in the inner Taurus Mountains. J. Ethnopharmacol. 1995, 46, 133-152.

20. Karim, H.; Boubaker, H.; Askarne, L.; Cherifi, K.; Lakhtar, H.; Msanda, F.; Aoumar, A. A. B. Use of Cistus aqueous extracts as botanical fungicides in the control of Citrus sour rot. Microb. Pathog. 2017, 104, 263-267.

21. Karim, H.; Boubaker, H.; Askarne, L.; Talibi, I.; Msanda, F.; Boudyach, E. H.; Ait Ben Aoumar, A. Antifungal properties of organic extracts of eight Cistus L. species against postharvest citrus sour rot. Lett. Appl. Microbiol. 2016, 62, 16-22.

22. Chen, C.; Long, L.; Zhang, F. Antifungal activity, main active components and mechanism of Curcuma longa extract against Fusarium graminearum. Sarrocco S, ed. PLoS One. 2018, 13(3), e0194284.

23. Booth, C. The genus Fusarium. The genus Fusarium. 1971. https://www.cabdirect.org/ cabdirect/abstract/19721603830.

24. Staats, M.; van Baarlen, P.; van Kan, J.A.L. Molecular Phylogeny of the Plant Pathogenic Genus Botrytis and the Evolution of Host Specificity. Mol. Biol. Evol. 2004, 22, 333-346.

25. He, L.; Liu, Y.; Mustapha, A.; Lin, M. Antifungal activity of zinc oxide nanoparticles against Botrytis cinerea and Penicillium expansum. Microbiol. Res. 2011, 166, 207-215.

26. Schmitz, H. Poisoned food technique. Industrial and Engineering Chemistry-Analytical Edition. 1930, 2, 361-363.

27. Ogbebor, O. N.; Adekunle, A. T.; Evueh, G. A. Inhibition of Drechslera heveae (Petch) MB Ellis, causal organism of Bird's eye spot disease of rubber (Hevea brasiliensis Muell Arg.) using plant extracts. Afr. J. Gen. Agric. 2oo8, 4, 19-26.

28. Keller, M.; Viret, O.; Cole, F. M. Botrytis cinerea infection in grape flowers: defense reaction, latency, and disease expression. Phytopathology. 2003, 93, 316-322.

29. Rheeder, J. P.; Marasas, W. F. O.; Thiel, P. G.; Sydenham, E. W.; Shephard, G. S.; Van Schalkwyk, D. J. Fusarium moniliforme and fumonisins in corn in relation to human esophageal cancer in Transkei. Phytopathology. 1992, 52, $35^{2}$. 